\title{
Intratumor injection of small interfering RNA-targeting human papillomavirus 18 E6 and E7 successfully inhibits the growth of cervical cancer
}

\author{
TAKUMA FUJII $^{1}$, MIYUKI SAITO ${ }^{1}$, ERI IWASAKI ${ }^{1}$, TAKAHIRO OCHIYA $^{2}$, YOSHIFUMI TAKEI $^{3}$, \\ SHIGENORI HAYASHI ${ }^{1}$, AKIKO ONO ${ }^{1}$, NOBUMARU HIRAO ${ }^{1}$, MASARU NAKAMURA ${ }^{1}$, \\ KANEYUKI KUBUSHIRO ${ }^{1}$, KATSUMI TSUKAZAKI ${ }^{1}$ and DAISUKE AOKI ${ }^{1}$ \\ ${ }^{1}$ Department of Obstetrics and Gynecology, Keio University School of Medicine, 35 Shinanomachi, \\ Shinjuku-ku, Tokyo 160-8582; ${ }^{2}$ Section for Studies on Metastasis, National Cancer Center Research Institute, \\ 1-1, Tsukiji 5-chome, Chuo-ku, Tokyo 104-0045; ${ }^{3}$ Department of Biochemistry, Nagoya University, \\ Graduate School of Medicine, 65 Tsurumai-cho, Showa-ku, Nagoya 466-8550, Japan
}

Received March 2, 2006; Accepted April 14, 2006

\begin{abstract}
Human papillomavirus (HPV) 18 is related not only to squamous cell carcinoma of the cervix, but also to adenocarcinoma and small cell carcinoma of the cervix, in which prognosis is known to be poor. Small interfering RNA (siRNA) that targets HPV18 E6 and E7 was tested in HPV18-positive cell lines to investigate its effect and investigate its mechanism of action. Nude mice were also tested in a combination of siRNA and atelocollagen to determine whether it might be useful as a new moleculetargeting therapy for cervical cancer. siRNAs targeting HPV18 E6 and E7 were transfected into cervical cancer cells in vitro and they were investigated for cell growth inhibition, expression of E6 and E7 mRNA, expression of retinoblastoma protein, and senescence-associated B-galactosidase staining. Sequence-specific siRNA inhibited cell growth. Decreased expression of E6 and E7 mRNA followed with E7 protein was observed in the transfected cells, but the expression of retinoblastoma protein and the B-galactosidase staining increased, suggesting cell growth inhibitory effect through senescence. Treatment of xenografts established from SKG-II cells with siRNA specific for E6 and E7 obviously suppressed tumor growth in vivo. These results indicate that atelocollagen-mediated delivery of siRNA HPV18 E6 and E7 can be used as a novel therapeutic approach for cervical cancer.
\end{abstract}

Correspondence to: Dr Takuma Fujii, Department of Obstetrics and Gynecology, Keio University School of Medicine, 35 Shinanomachi, Shinjuku-ku, Tokyo 160-8582, Japan

E-mail: fujiit@sc.itc.keio.ac.jp

Key words: small interfering RNA, cervical cancer, human papillomavirus, atelocollagen, animal model

\section{Introduction}

Molecule-targeting therapy with small interfering RNA (siRNA) is expected to prevent the development of diseases caused by foreign genes, such as human immunodeficiency virus infection, by inhibiting expression of the genes (1). Since human papillomavirus (HPV) infects the uterine cervix and is widely recognized as a risk factor for cervical cancer (2), molecule-targeting therapy of cervical cancer with siRNA targeted against HPV genomes is viewed with hope. HPV genomes have been isolated from $>90 \%$ of squamous cell carcinomas of the cervix, and HPV16 has been isolated from approximately half of them $(3,4)$. HPV18 is reported to be present in squamous cell carcinoma of the cervix (5) and is one of the most frequent types of HPV isolated from adenocarcinoma of the cervix (6), and is also very frequently isolated from small cell carcinoma (7). Since the prognosis of adenocarcinoma and small cell carcinoma has been found to be worse clinically than that of squamous cell carcinoma, infection by HPV18 may contribute to cervical cancer with a poor prognosis. We have established and investigated SKG cell lines derived from HPV-positive squamous cell carcinoma of the cervix in our laboratory $(8,9)$. Since both E6 and E7 genes are always expressed in HPV-positive cells, in this study we designed siRNA that targets HPV18 E6 and E7 and investigated its efficacy and mechanism of action in HPV18-positive cell lines derived from squamous cell carcinoma. Furthermore, delivering the molecule in vivo would present a problem if oligonucleotides were used as a means of molecule-targeting therapy in the future, atelocollagen has been spotlighted as a tool to enable reliable delivery and use of unstable siRNA in vivo (10-17). Atelocollagen is a highly purified type I collagen of calf dermis with pepsin treatment. Atelocollagen allowed increased cellular uptake, nuclease resistance and prolonged release of siRNA. We therefore used nude mice to assess whether combining siRNA with atelocollagen might be useful as a new method of molecule-targeting therapy for cervical cancer. 


\section{Materials and methods}

siRNA transfection and cell proliferation. SKG-II cells and SKG-IIIa cells derived from human cervical cancer were established in our laboratory. SKG-II cells and HeLa cells contained the HPV18 genome, whereas SKG-IIIa cells contained the HPV16 genome (18). SKG-II, and SKG-IIIa cells were cultured in Ham's F-12 medium with $10 \%$ heat inactivated fetal bovine serum, and HeLa cells were cultured in Dulbecco's modified Eagle's medium (DMEM) with $10 \%$ heat inactivated fetal bovine serum, at $37^{\circ} \mathrm{C}$ in a humidified atmosphere of $5 \% \mathrm{CO}_{2}$. The SKG-II and SKG-IIIa cells were plated at a density of $1 \times 10^{5}$ cells in a 6 -well plate, and HeLa cells were plated at a density of $0.4 \times 10^{5}$ in a 6 -well plate. After $20 \mathrm{~h}$ in the condition of $30 \%$ confluence, the cells were transfected with siRNAs in OPTI-MEM I Reduced-Serum Medium (Invitrogen Corp., Carlsbad, CA, USA) by using sureFECTOR (B-Bridge International, Inc., Sunnyvale, CA, USA). The siRNAs were designed by B-Bridge International Inc. and all siRNAs were synthesized by Dharmacon Research, Inc. (Lafayette, CO, USA).

Briefly, $1 \mu \mathrm{l}$ of each siRNA stock solution $(20 \mu \mathrm{M})$ and $99 \mu 1$ of OPTI-MEM I medium were mixed in a small sterile tube, and while that solution was being incubated, $3 \mu 1$ of sureFECTOR and $97 \mu 1$ of OPTI-MEM I medium were mixed in another tube. The two mixtures were then combined and incubated at room temperature for $15 \mathrm{~min}$. A $800 \mu \mathrm{l}$ volume of OPTI-MEM medium was then added, and the entire mixture was added to the cells. After incubation for $5 \mathrm{~h}$ at $37^{\circ} \mathrm{C}, 1 \mathrm{ml}$ of medium containing $20 \%$ fetal bovine serum was added to the cells, and incubation continued for $24 \mathrm{~h}$. The fresh medium was then replaced. Incubation with siRNA, final concentration $20 \mathrm{nM}$, was again performed for $48 \mathrm{~h}$ and the fresh medium was replaced at $72 \mathrm{~h}$. The cells were harvested and counted for analysis at least six times and one representative result is shown.

Quantitative real-time RT-PCR assay. SKG-II and HeLa cells were seeded onto 6-well plates. For the quantitative realtime RT-PCR, SKG-II and HeLa cells which were tranfected a mixture of \#1 (or GL-2) siRNA and sureFECTOR, were harvested in $36 \mathrm{~h}$ and $24 \mathrm{~h}$, respectively. Final concentration of siRNA was $20 \mathrm{nM}$. Total RNA was isolated by the guanidine isothiocyanate method (Isogen, Nippon Gene, Toyama, Japan) according to the manufacturer's instructions. Quantitative realtime reverse transcription-PCR (RT-PCR) was performed with the TaqMan ${ }^{\circledR}$ One-Step RT-PCR Master Mix Reagents Kit (Applied Biosystems, CA, USA) using the following primers and a probe set for detection of HPV18E6E7 transcripts: forward primer, 5'-CTGATCTGTGCACGGAAC TGA-3' (148-168); reverse primer, 5'-TGTCTAAGTTTTTC TGCTGGATTCA-3' (439-463); and a probe, 5'-TTGG AACTTACAGAGGTGCCTGCGC-3' (219-233 and 416-425). The probe was labeled at the $5^{\prime}$ end with a reporter fluorescent dye, 6-carboxylfluorescein, FAM ${ }^{\mathrm{TM}}$ and at the $3^{\prime}$ end with a fluorescent dye quencher, carboxytetramethylrhodamine, TAMRA $^{\text {TM }}$. A TaqMan ${ }^{\circledR}$ GAPDH Control Reagents Kit (Applied Biosystems) was used to detect human glycelaldehyde-3-phosphate dehydrogenase (GAPDH) transcripts for the normalization (calibrator). Briefly, the reaction mixture for detection of HPV18E6E7 contained 1X Master Mix without uracil-N-glycosylase (UNG), 1X MultiScribe and RNase Inhibitor Mix, $300 \mathrm{nM}$ forward and reverse primers, $240 \mathrm{nM}$ Taqman probe, $10 \mathrm{ng}$ total RNA, and water was added to a final volume of $50 \mu \mathrm{l}$. The reaction mixture for detection of GAPDH contained 1X Master Mix without UNG, $1 \mathrm{X}$ MultiScribe and RNase Inhibitor Mix, $300 \mathrm{nM}$ forward primer, $300 \mathrm{nM}$ reverse primer, $250 \mathrm{nM}$ Taqman probe, $10 \mathrm{ng}$ total RNA, and water was added to a final volume of $50 \mu \mathrm{l}$. Reverse transcription was performed at $48^{\circ} \mathrm{C}$ for $30 \mathrm{~min}$ and followed by reaction at $95^{\circ} \mathrm{C}$ for $10 \mathrm{~min}$. PCR amplification for 40 cycles as performed by denaturation at $95^{\circ} \mathrm{C}$ for $15 \mathrm{sec}$ and annealing at $60^{\circ} \mathrm{C}$ for $1 \mathrm{~min}$ in the Applied Biosystems 7700 Sequence Detector system. A comparative threshold cycle $(\mathrm{Ct})$ was used to determine gene expression relative to the control (calibrator). Hence, steady-state mRNA levels were expressed as an $n$-fold difference relative to the calibrator. For each sample, the E6E7 Ct value was normalized using the formula: $\Delta \mathrm{Ct}=\mathrm{CtE6E7}$ - CtGAPDH (19). To determine relative expression levels, the following formula was used: $\Delta \Delta \mathrm{Ct}=\Delta \mathrm{Ct}$ sample - $\Delta \mathrm{Ct}$ calibrator and the value used to plot relative E6E7 expression was calculated using the expression $2^{-\Delta \Delta C t}$. The mRNA levels were calibrated by GAPDH transcripts and the mRNA level of no treatment of cells was defined as one A.U.

Immunoblotting. HeLa cells and SKG-II cells transfected with \#1 siRNA were harvested in 72 and $120 \mathrm{~h}$ after transfection, respectively. The transfected cells were washed with PBS and lysed with lysis buffer containing $50 \mathrm{mM}$ Tris- $\mathrm{HCl}$ ( $\mathrm{pH}$ 8.0), $150 \mathrm{mM} \mathrm{NaCl}, 0.02 \% \mathrm{NaN}_{3}, 1 \% \mathrm{NP}-40,0.1 \%$ SDS, $0.5 \%$ sodium deoxycholate, $10 \mu \mathrm{g} / \mathrm{ml}$ aprotinin, $5 \mu \mathrm{g} / \mathrm{ml}$ leupeptin and $5 \mu \mathrm{g} / \mathrm{ml}$ pepstatin. After shearing the collected cells with a $26 \mathrm{G}$ needle three times, an equal volume of $2 \mathrm{X}$ SDS sample buffer containing $120 \mathrm{mM}$ Tris- $\mathrm{HCl}$ (pH 6.8), 4\% SDS, 20\% glycerol, $0.1 \%$ bromophenol blue and $100 \mu \mathrm{l} / \mathrm{ml}$ $\beta$-mercaptoethanol was added, and the solution was boiled for $5 \mathrm{~min}$. The samples were briefly centrifuged and loaded onto the polyacrylamide concentration gradient gel (Daiichi Pure Chemicals, Tokyo, Japan). After electrophoresis, the proteins were transferred to a Hybond-P PVDF membrane (Amersham Biosciences, Piscataway, USA). The membrane was blocked at $4^{\circ} \mathrm{C}$ for $12 \mathrm{~h}$ with a solution TBS-T containing $5 \%$ non-fat dry milk, $10 \mathrm{mM}$ Tris- $\mathrm{HCl}(\mathrm{pH} 7.5), 150 \mathrm{mM}$ $\mathrm{NaCl}, 0.02 \%$ Tween-20 and $0.1 \% \mathrm{NaN}_{3}$, followed by incubation at room temperature for $1.5 \mathrm{~h}$ with mouse monoclonal anti-Rb antibody (G3-245, Biosciences PharMingen, San Jose, CA, USA), p53 (PAb1801, Novocastra, Newcastle upon Type, UK) and goat polyclonal anti HPV-18E7 antibody (sc-1590, Santa Cruz Biotechnology, CA, USA) at 1-250, 100 , and 1000 dilution, respectively. The membrane was washed in TBS-T and incubated at room temperature for $1 \mathrm{~h}$ with horseradish-peroxidase-conjugated sheep anti-mouse $\operatorname{IgG}$ at 1-2000 dilution for anti-Rb and p53 antibody, and donkey anti-goat IgG at 1-2000 dilution for anti-E7 antibody. The membrane was then washed in TBS-T, and detection was performed with ECL Western blotting detection reagents (Amersham Biosciences).

Senescence-associated $\beta$-galactosidase staining. SKG-II cells were fixed in 5 days after transfection. Cells were washed in 
PBS, fixed for 3-5 min in 2\% formaldehyde and $0.2 \%$ glutaraldehyde, washed, and incubated at $37^{\circ} \mathrm{C}$ with fresh senescence associated (SA)- $3-$ Gal stain solution containing $1 \mathrm{mg}$ of 5-bromo-4-chloro-3-indolyl ß-D-galactoside per ml, $40 \mathrm{mM}$ citric acid, sodium phosphate, $\mathrm{pH} 6.0,5 \mathrm{mM}$ potassium ferrocyanide, $5 \mathrm{mM}$ potassium ferricyanide, $150 \mathrm{mM} \mathrm{NaCl}$ and $2 \mathrm{mM} \mathrm{MgCl} 2$.

Experimental tumor therapy. A total of $2 \times 10^{6}$ SKG-II cells in $0.5 \mathrm{ml}$ of PBS were inoculated with a $26 \mathrm{G}$ needle into the back of 8-week-old athymic nude mice obtained from Nihon Clea Japan Inc. One week later, when the tumors had reached an average volume of 50-60 $\mathrm{mm}^{3}$, the tumors-bearing mice were treated with \#1 siRNA, target for E6 and E7 mRNA, with atelocollagen (Koken Co. Ltd., Tokyo, Japan). The final concentration of atelocollagen was $0.9 \%$ and the amount of siRNA was one nanomole. The total volume of therapeutic reagent diluted with PBS was $30 \mu 1$. The equal amount of GL2 siRNA, target for pGL2 control vector (GenBank $\mathrm{X} 65324)$, with atelocollagen was injected as a negative control. Each therapeutic reagent was again injected into the tumors 10 days after the first treatment. Tumor diameter was measured with calipers at regular intervals, and the tumor volume was calculated by the following formula: volume = (width) $)^{2} \mathrm{x}$ length/2. The animal experiments complied with the guidelines of the Institute for Laboratory Animal Research of Keio University School of Medicine.

Determination of tumor growth index in nude mouse tumor. The tumors on day 28 were resected, and tissue sections for immunohistochemistry from a formalin-fixed, paraffinembedded block were mounted on a saline-coated glass slide, dewaxed in xylene. The slides were pretreated with Target Retrival Solution (Dako, Kyoto, Japan) at $121^{\circ} \mathrm{C}$ for $10 \mathrm{~min}$. Endogenous peroxidase activity was blocked with Peroxidase-Blocking Solution (Dako) for $5 \mathrm{~min}$. The primary antibody, mouse anti-Ki-67 monoclonal antibody (MIB-1, Dako) was diluted 1:100 in Antiboby Diluent (Dako) and was incubated for $1 \mathrm{~h}$ at room temperature. Slides were exposed to ENVISION+ (Dako) for $30 \mathrm{~min}$, and peroxidase activity was visualized with DAB Liquid (Dako). Finally, the slides were counterstained with hematoxylin. The tumor cell proliferation was assessed using Ki-67 labeling, and all cell nuclei staining brown, regardless of intensity, were considered positively labeled. These indices were calculated in each five high-power fields selected at random, and 100 cancer cells were evaluated to obtain the rate of positively stained cells. These indices were determined as the ratio of positively labeled cells to all cells and are expressed as a percentage.

Statistical analysis. Statistical analysis was performed by SPSS 13.0 program. Inhibitory effect on cell proliferation, real-time RT-PCR, and tumor therapy experiments were analyzed by Tukey multiple comparison test, $\chi^{2}$-test, and Mann-Whitney's $\mathrm{U}$ test, respectively.

\section{Results}

Sequence-specific siRNA suppressed cell proliferation. It was difficult to transfect the series of SKG cell lines by conventional
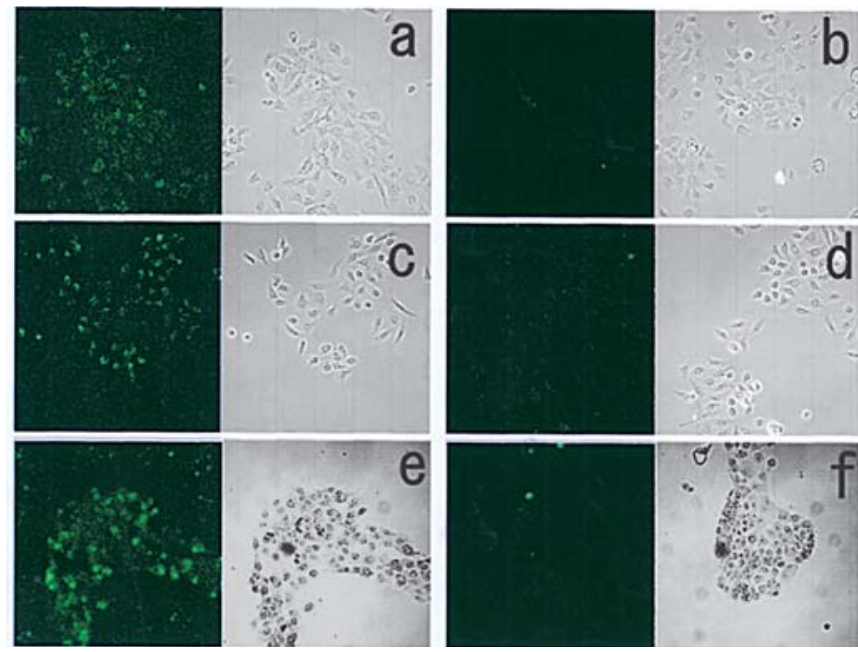

Figure 1. Transfection efficiency of siRNA in cell lines. SKG-II cells (a and b) and HeLa cells (c and d) which contained HPV18 DNA, and SKG-IIIa cells (e and f) which contained HPV16 DNA, were examined by fluorescent image (left panel) or transmission image (right panel). Cells were transfected with a mixture of fluorescent-GL-2 and sureFECTOR (a, c and e) or mock transfected with sureFECTOR (b, d and f) and examined after 72-h transfection.
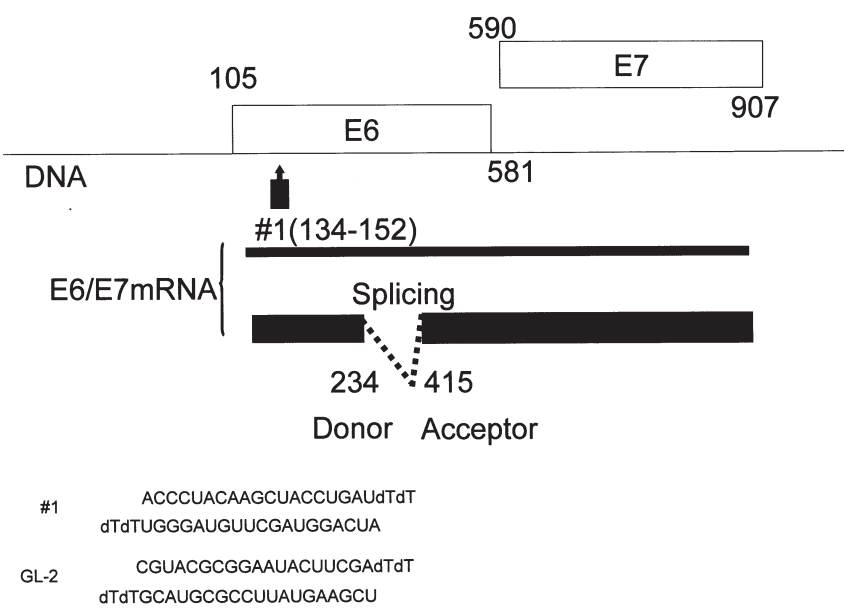

Figure 2. Location of the siRNA sequences to inhibit the growth in HPV18 positive cell lines. The HPV18 E6 and E7 open reading frames and their mRNAs are indicated. The numbers on the DNA are cited from the sequence number (GenBank accession no. X05015). Minor unspliced and major spliced E6/E7 mRNA are shown. Major mRNA is spliced at the position 234-415 nt. The location of the candidate siRNAs is indicated by \#1. The sequences of the \#1 and control GL-2 siRNAs are described below.

electroporation, calcium precipitation or certain liposome reagents. We tried using Fugene 6 (Roche Diagnostics Corporation, Indianapolis, IN, USA), oligofectamine (Invitrogen Corporation), Unifector (B-Bridge International) and sureFECTOR reagents to transfect SKG cells, and achieved the highest transfection efficiency with sureFECTOR. In order to monitor the transfection efficiency of siRNA, fluorescein-labeled luciferase GL-2 siRNA, which original sequence was derived from GL-2 control vector, was transfected with sureFECTOR into various cervical cancer cell lines. A fluorescence signal was observed in $98 \%$ of the three cell lines (Fig. 1). Several candidate siRNA sequences calculated by algorism by B-Bridge Inc., were selected to assess suppression of E6 and E7 transcripts, however, only \#1 siRNA 


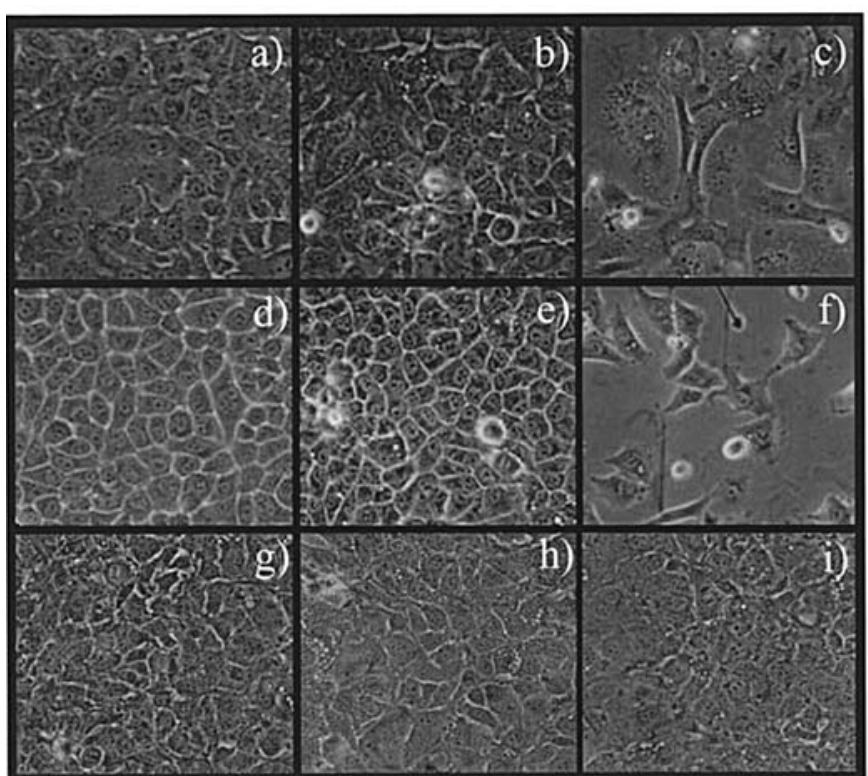

Figure 3. Morphological changes in cell lines transfected with \#1 siRNA. SKG-II (a, b, c, g, h and i) and HeLa cells (d, e and f) were examined by light microscopy. Transfected cells were observed by no treatment (a, d, and g), treatment by sureFECTOR ( $b$, e and $f$ ) alone and treatment by \#1 siRNA (c and f) or GL-2 siRNA (i) along with sureFECTOR after 5 days (SKG-II cells) or 3 days (HeLa cells) transfection.
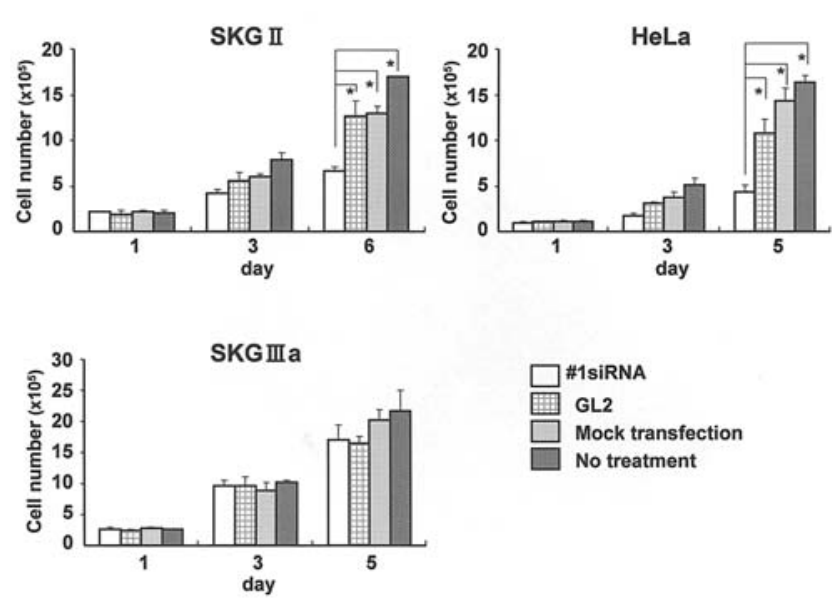

Figure 4. Inhibitory effect of siRNA on cell proliferation in various cervical cancer cell lines. Cell survival was monitored by cell counting. Days after transfection are shown on the $\mathrm{x}$-axis, and cell number $\left(1 \mathrm{x} 10^{5}\right)$ on the $\mathrm{y}$-axis. \#1 and GL2 siRNA was transfected into SKG-II, HeLa and SKG-IIIa cells, respectively. Mock indicated cells treated with sureFECTOR only. Asterisk indicates statistical significance $(\mathrm{P}<0.05)$.

showed inhibitory effect on the cell proliferation. \#1 siRNA was located in the 5'-prime lesion of the E6 open reading frame (ORF) in Fig. 2. The location of \#1 siRNA sequence was overlapping the sequence in a previous report (20), however, not identical. As shown in Fig. 3, sureFECTOR alone had no effect on SKG-II cells. Although sureFECTOR appeared to cause slight morphological changes in HeLa cells, it did not seem to cause problems in terms of judging the effects of introduction of siRNA. Whenever substantial cell swelling and elongation of the cytoplasm was observed as a result of introduction of \#1 siRNA, a simultaneous reduction in the number of cells that had attached to the plate was also observed.

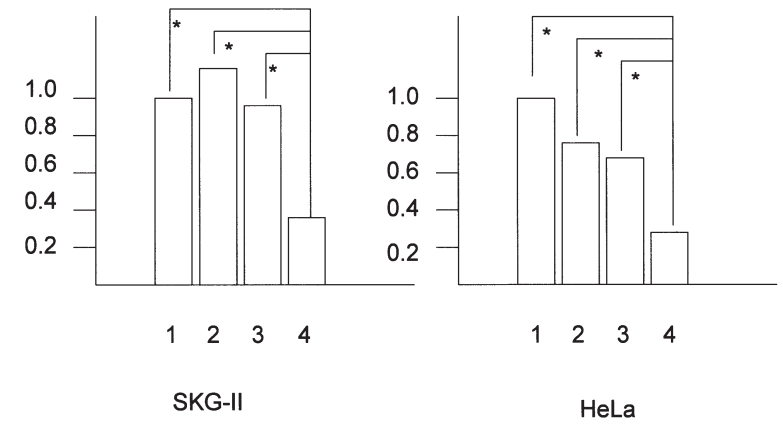

Figure 5. Estimation of HPV18 and E7 transcripts by real-time RT-PCR SKG-II cells and HeLa cells were transfected with a mixture of \#1 (or GL-2) siRNA and sureFECTOR, and harvested at $36 \mathrm{~h}$ and $24 \mathrm{~h}$, respectively. E6 and E7 transcripts were investigated by real-time RT-PCR. GAPDH transcript was amlified for normalization as a calibrator. No treatment, 1 ; sureFECTOR alone, 2; transfection with GL-2 siRNA, 3; transfection with \#i siRNA, 4. The mRNA levels were calibrated by GAPDH transcripts and the mRNA level of no treatment of cells was defined as one A.U. in the vertical bar. Asterisk indicates statistical significance $(\mathrm{P}<0.001)$ between \#1 (4) and controls $(1-3)$.

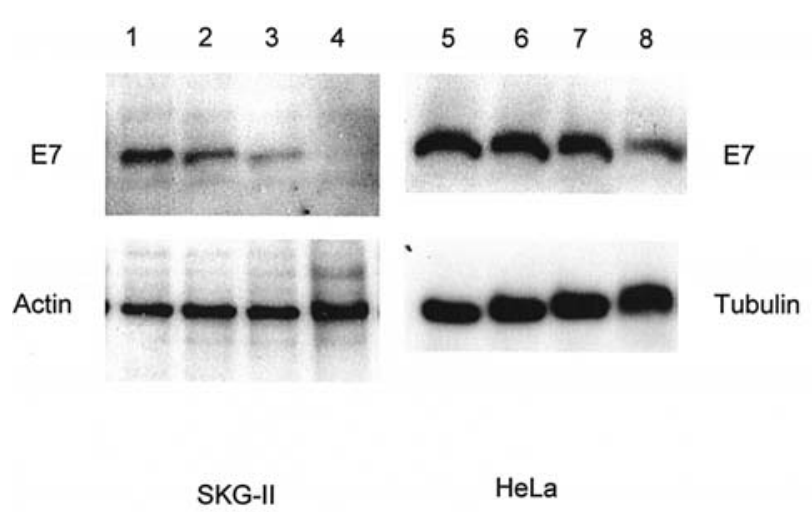

Figure 6. Detection of the level of E7 protein expression by Western blot analysis in the cell lines. No treatment in lanes 1 and 5; mock transfection, sureFECTOR alone in lanes 2 and 6; transfection with GL-2 siRNA in lanes 3 and 7; transfection with \#1 siRNA in lanes 4 and 8 (upper panel). The internal control, actin or tubulin mRNA is shown in cell lines (bottom panel).

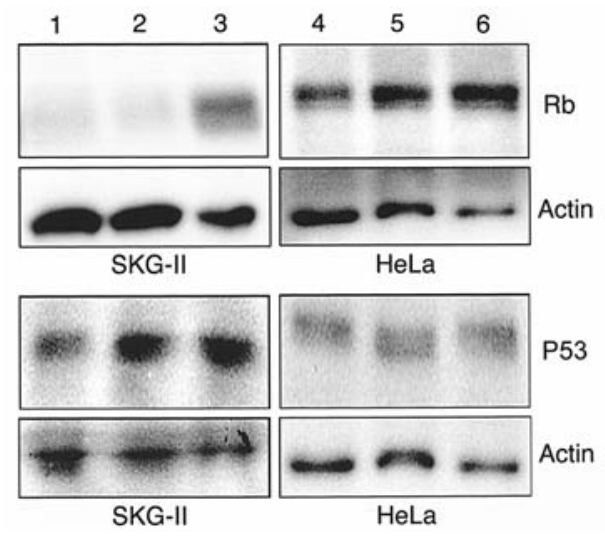

Figure 7. Detection of the level of Rb protein and $\mathrm{p} 53$ protein expression by Western blot analysis in the cell lines: no treatment in lanes 1 and 4; mock transfection, sureFECTOR alone in lanes 2 and 5 ; transfection with \#1 siRNA in lanes 3 and 6 .

For the cell proliferation assay, the cells transfected with the candidate siRNA were harvested and counted for analysis 
as shown in Fig. 4. Only \#1 siRNA inhibited the growth of SKG-II and HeLa cells, however, it did not inhibit the growth of SKG-IIIa cells. GL-2 siRNA as a negative control did not inhibit growth of the SKG-II cells either.

Suppression of the E6 and E7 mRNA by siRNA. The expression level of the HPV18 E6 and E7 transcripts in SKG-II cells has been reported by Northern blot analysis $(8,9)$. \#1 siRNA suppressed approximately $70 \%$ and $50 \%$ of the original mRNA in SKG-II and HeLa cells, respectively. GL-2 siRNA did not affect the mRNA expression level in the transfected cells (Fig. 5).

Down-regulation of $\mathrm{E} 7$ protein followed by retinoblastoma protein recovers in cells transfected with sequence-specific SiRNA. Western blot analysis was performed to detect the effect of siRNA on the expression of E7 protein level, but the band of E7 in the \#1 treated cells was not detected in SKG-II cells (Fig. 6, lane 4). The densitometry showed that E7 protein decreased about 0.6 -fold in \#1 siRNA trasfected HeLa cells, compared to the mock-transfected control cells (Fig. 6, lanes 6 and 8). Western blot analysis was also performed to detect the effect of siRNA on the expression of $\mathrm{Rb}$ protein level, and densitometry showed that it increased about 5.5- and 1.5-fold in \#1 siRNA-trasfected SKG-II and HeLa cells, respectively, compared to the mock-transfected control cells. In contrast, P53 protein level was not increased with \#1 siRNA treatments (Fig. 7).

Sequence-specific siRNA expresses SA-B-Gal. We investigated whether the decrease in proliferation was due to apoptosis or senescence. Since the cells transfected with \#1 siRNA were viable according to the results of trypan blue staining (data not shown), SA-ß-Gal staining was performed. SKG-II cells treated with \#1 siRNA expressed SA-B-Gal, implying that the inhibition of cell growth after transfection with \#1 siRNA was due to senescence (Fig. 8).

Treatment of the established SKG-II cell xenografts with E6E7 siRNA. SKG-II cells were injected into back of the nude mice, and 1 week later visible tumors had developed at the injection sites (tumor volume, 50-60 $\mathrm{mm}^{3}$ ). To determine the therapeutic effectiveness of E6 and E7 siRNA, intratumoral injection of a mixture of \#1 siRNA and atelocollagen or a mixture of GL-2 siRNA and atelocollagen was administered and repeated in 10 days because mixture with atelocollagen and siRNA was stable for this period (15). The tumor volume treated with \#1 siRNA was one-fifth volume of those treated with GL-2 siRNA or no treatment group (Fig. 9a and b). This experiment was performed three times and one representative is shown. No adverse effect such as loss of body weight was observed during the experimental period. In order to examine the cell proliferation activity between \#1 and GL-2 treated tissues, Ki-67 immnostaining is shown in Fig. 9c. In the \#1 treated tissues, the Ki-67 labeling index ranged from $65 \%$ to $75 \%$ with a mean value of $71 \pm 4 \%$. In the GL-2 siRNAtreated tissues, the Ki-67 labeling index ranged from $85 \%$ to $92 \%$ with a mean value of $88 \pm 2.5 \%$. The Ki-67 index was lower in \#1 treated tissues than in GL-2 treated tissues $(\mathrm{P}=0.02)$.

\section{Discussion}

Suppression of target genes is known to be more sufficient by siRNA produced by retrovirus vectors than by synthetic siRNA. However, toxicology data obtained with viral vectors are likely to have been derived largely from experiments in humans (21), whereas non-viral vehicles are likely to present minimal toxic or immunological problems. The E6 mRNA and E7 mRNA of HPV16 and HPV18 have been reported to be candidate therapeutic targets for cervical cancer from in vitro experiments $(20,22,24)$, but to our knowledge there have been no reports of experimental therapy targeting E6 and E7 in vivo. We therefore designed several synthetic siRNAs targeting the HPV18 E6 and E7 region, including the E6 splice out region, the 3'- and 5'-prime of the region of the ORF of both E6 and E7, and screened them for their ability to inhibit proliferation in SKG-II cells. The results showed that only \#1 siRNA clearly inhibited cell growth. The \#1 siRNA was then tested on other cells containing the HPV18 E6 and E7 ORF, i.e., HeLa cells, and similar results were obtained (Fig. 4). Butz et al reported that siRNA targeting HPV18 E6 inhibits cell growth by the spliced out of the E6 region in HeLa cells (23). The difference between the findings of Butz et al and ours may be attributable to the difference in the siRNA expression system. The fact that \#1 siRNA is located on the 5'-prime region of the E6 gene suggested that it inhibits expression of both the E6 gene and E7 gene. Since both E6 and $\mathrm{E} 7$ proteins are produced by the same transcriptional unit, it is difficult to knock down the individual genes separately. As reported by DeFilippis et al, the only method currently available consists of introducing another type of E6 gene and/or E7 gene into cells in which E6 and E7 have been knocked out (25).

To assess whether the siRNA we designed had blocked the E6-p53 pathway or the E7-Rb pathway, we used Western blot analysis to investigate the expression levels of p53 protein, the target of E6, and of Rb protein, the target of E7. Expression of $\mathrm{Rb}$ protein increased in both SKG-II and HeLa cells. By contrast, no increase of p53 protein level was observed in SKG-II or HeLa cells. We also investigated expression of $\mathrm{p} 21$ protein, the target protein of $\mathrm{p} 53$ protein, by similar methods, but no changes were detected (data not shown). We assume that it may be difficult to show recovery of p53 expression by our synthetic siRNA, because the change in p53 expression in our system may be too subtle. Alternatively, death of p53-positive cells could explain their disappearance during the observation period. After exposure to synthetic siRNA, expression of p53 protein has been reported to recover instantly but subsequently to diminish quickly in a matter of hours (26). By contrast, Yoshinouchi et al (22) and Jiang and Milner (24) observed clear p53 recovery with siRNA trasnfection against HPV16. There is a report that different patterns of rescue of p53 protein by proteasome inhibitors, which is equivalent to blocking E6 with siRNA, were observed among cancer cells, but not in HeLa cells (27). The association between E6 protein and p53 protein in HeLa cells containing the HPV18 genome may be different from their association in SiHa cells containing the HPV16 genome. The differences of the effect of \#1siRNA on the level of expression of $\mathrm{Rb}$ protein or $\mathrm{p} 53$ protein in these 


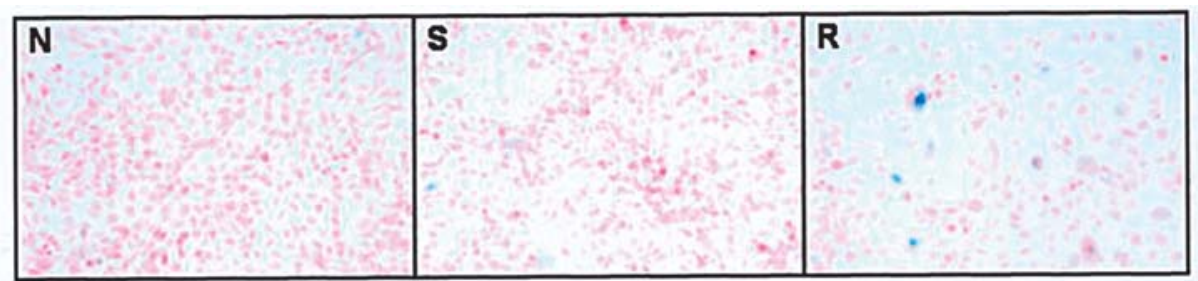

Figure 8. Induction of SA-ß-Gal expression in SKG-II cells transfected with \#1 siRNA. SKG-II cells were stained for SA-ß-Gal and counterstained with nuclear fast red. (N) No treatment. (S) Mock transfection with sureFECTOR. (R) \#1 siRNA transfected with sureFECTOR. Scenescence cells are shown by blue color.

a

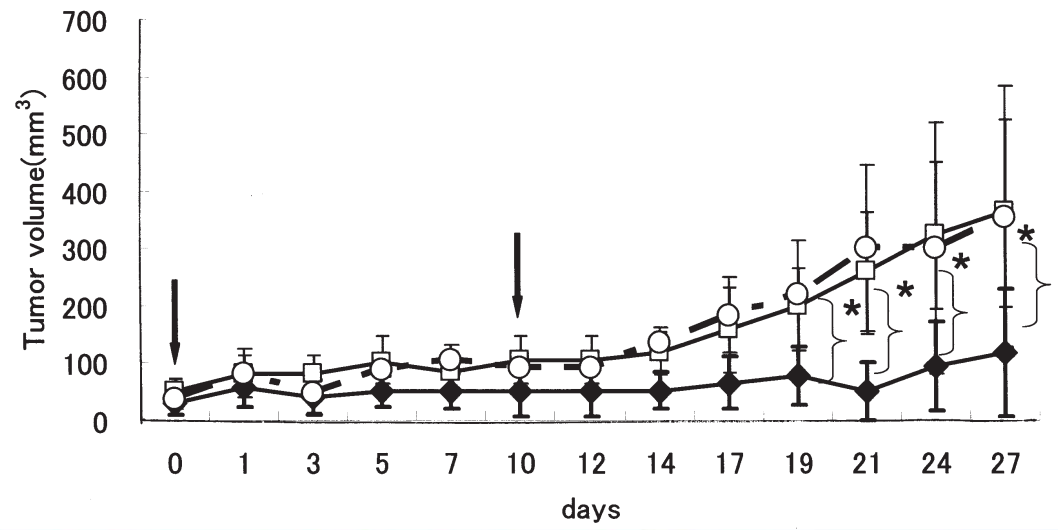

b

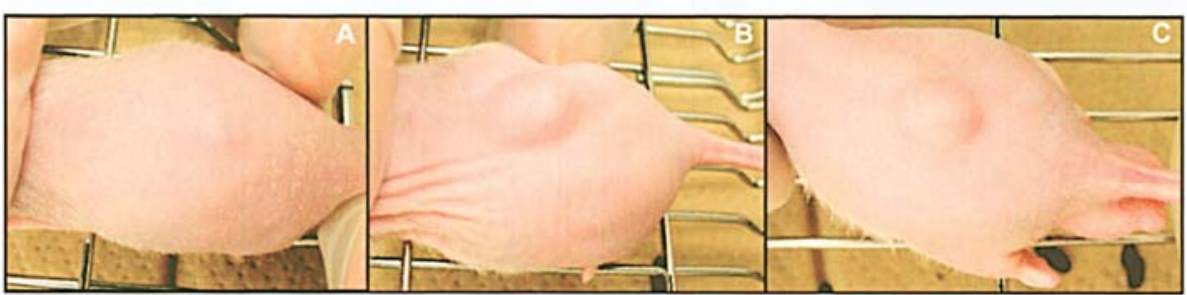

c

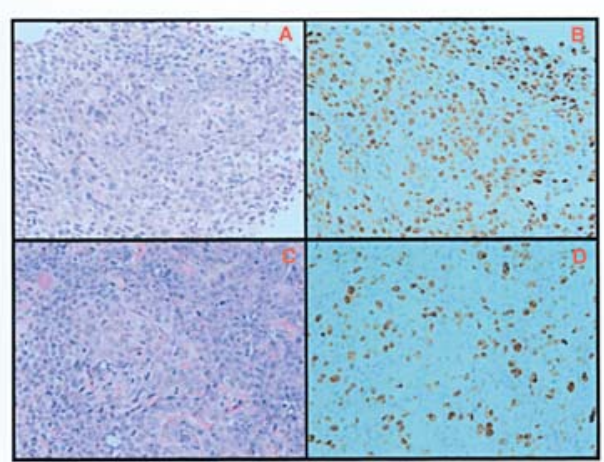

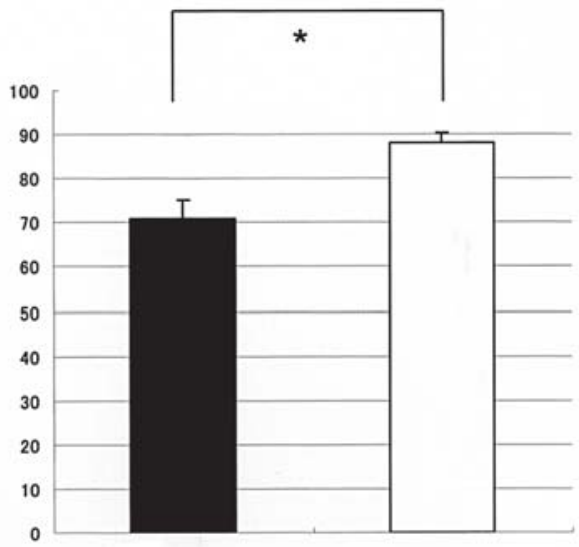

\#1

GL-2

Figure 9. Antitumor effect of \#1 siRNA in SKG-II tumor-bearing nude mice. On days 0 and 10, \#1 siRNA (black diamond, 1 nano mole) or GL-2 siRNA (square, 1 nano mole) was mixed with atelocollagen, and $30 \mu 1$ of each mixture was injected into the tumor region (indicated by arrows). No treatment is indicated by a circle. Six mice were treated with both \#1 and GL-2 siRNA, and no treatment of 3 mice were investigated. Day 0 corresponds to 7 days after inoculation of the cells, when tumor volume had reached approximately $50 \mathrm{~mm}^{3}$. (A) Tumor growth curve. Tumor diameter was measured with calipers for up to $27 \mathrm{days}$, and tumor volume was calculated. The antitumor effect between mice treated with \#1 and GL-2 siRNA was statistically significant $(*)$ by Mann-Whitney's U test $(\mathrm{P}<0.05)$. (B) Photograph of SKG-II xenografts. During \#1 siRNA treatment, SKG-II tumors were photographed on day 21. (A) \#1 siRNA (B) GL-2 siRNA (C) no treatment. (C) Ki-67 immunostaining of the resected mouse tumor. Left panel, tumor by H.E. (A and C) and Ki-67 immunostaining (B and D). GL-2 siRNA treated tumor (A and B), and \#1 siRNA treated tuomor (C and D), respectively. Right panel, the Ki-67 labeling index was statistically significant $(*)$ by Mann-Whitney's $\mathrm{U}$ test $(\mathrm{P}=0.002)$.

cells was thought to be primarily attributable to differences in the HPV subtype.

Cell growth inhibition is known to result from the cell death through the direct p53 pathway or senescence through the Rb pathway. HPV mRNA has been shown to be degraded by siRNA, but the mechanism of cell growth inhibition is still controversial. In some studies, recovery of $\mathrm{p} 53$ protein inhibited cell growth without inducing apoptosis $(22,24)$, 
whereas in another study the main outcome was apoptosis (23). In our experiments, no staining with trypan blue was observed in cells whose growth had been inhibited; no cell death pattern was found by FACS analysis; and no DNA strand breaks were detected in apoptotic cells by the TUNEL detection method (data not shown). Since positive SA-ß-Gal staining has been reported to be a marker of senescence in keratinocytes (28), we investigated and found the cells into which \#1 siRNA had been introduced stained positive. Thus, the mechanism of the cell growth-inhibiting effect appeared to be induction of senescence by \#1 siRNA through the E7-Rb pathway. As shown in Fig. 3, cell swelling and elongation of the cytoplasm were observed in the cells into which \#1 siRNA had been introduced, as during keratinocytes senescence (28).

The rationale for suppression of the E6 and E7 genes with antisense oligonucleotides or vectors has been reported previously $(29,30)$. The problem with these strategies was the lack of a delivery system in vivo, and viral vectors entail the problem of severe side effects irrespective of the high reduction in mRNA levels. Combination with agarose gel and siRNA to cervical cancer cells induces apoptosis in vitro (31). Atelocollagen and siRNA combination is resistant to siRNA degradation in the presence of nuclease (11) and contributes to the increased stability of siRNA injected into tumors (15). We therefore investigated whether \#1 siRNA has an inhibitory effect on tumor growth in nude mice, and the results showed that \#1 siRNA inhibited the growth of the tumors that formed in the nude mice. Administration of the \#1 siRNA and sureFECTOR mixture, on the other hand, had no inhibitory effect on tumor growth (data not shown). This means that an adequate therapeutic effect can be anticipated if \#1 siRNA is injected with atelocollagen as a carrier into cancer tissue. In the resected tumor, the cell proliferation activity was shown to be down-regulated by Ki-67 labeling. The results of in vitro experiments have suggested that the mechanism of the tumor growth-inhibiting effect of the mixture in vivo is induction of senescence.

This is the first report of inhibition of tumor growth derived from cervical cancer cells with a mixture of siRNA targeting HPV gene and atelocollagen. Cervical cancer has the advantage of allowing macroscopic observations of the cervix, the site where it arises, and the anatomical advantage of permitting the performance of local therapy. The combination of \#1 siRNA and atelocollagen, which is likely to exert a cytostatic effect, has the potential to become an important candidate for a new treatment of cervical cancer, in combination with anti-cancer drugs, which have cytocidal effects (26).

\section{Acknowledgments}

We thank Koken Co. Ltd., Tokyo, Japan, for providing atelocollagen; supported by Grant-in-Aid for Science (A) (C) Japan Society for the promotion of science and research for Life Science and Medicine.

\section{References}

1. Novina CD, Murray MF, Dykxhoorn DM, Beresford PJ, Riess J, Lee SK, Collman RG, Lieberman J, Shankar P and Sharp PA: siRNA-directed inhibition of HIV-1 infection. Nat Med 8: 681-686, 2002.
2. Zur Hausen H: Viruses in human cancers. Science 254: 1167-1173, 1991.

3. Masumoto N, Fujii T, Ishikawa M, Mukai M, Saito M, Iwata T, Fukuchi T, Kubushiro K, Tsukazaki K, and Nozawa S: Papanicolaou tests and molecular analyses using new fluid-based specimen collection technology in 3000 Japanese women. Br J Cancer 88: 1883-1888, 2003.

4. Masumoto N, Fujii T, Ishikawa M, Mukai M, Ono A, Iwata T, Kubushiro K and Nozawa S: Dominant human papillomavirus 16 infection in cervical neoplasia in young Japanese women; study of 881 outpatients. Gynecol Oncol 94: 509-514, 2004.

5. Franceschi S: The IARC commitment to cancer prevention: the example of papillomavirus and cervical cancer. Recent Results Cancer Res 166: 277-297, 2005.

6. Ishikawa M, Fujii T, Masumoto N, Saito M, Mukai M, Nindl I, Ridder R, Fukuchi T, Kubushiro K, Tsukazaki K and Nozawa S: Correlation of p16INK4A overexpression with human papillomavirus infection in cervical adenocarcinomas. Int J Gynecol Pathol 22: 378-385, 2003.

7. Masumoto N, Fujii T, Ishikawa M, Saito M, Iwata T, Fukuchi T, Susumu N, Mukai M, Kubushiro K, Tsukazaki K and Nozawa S: P16 overexpression and human papillomavirus infection in small cell carcinoma of the uterine cervix. Hum Pathol 34: 778-783, 2003.

8. Takebe N, Tsunokawa Y, Nozawa S, Terada M and Sugimura T: Conservation of E6 and E7 regions of human papillomavirus types 16 and 18 present in cervical cancers. Biochem Biophys Res Commun 143: 837-844, 1987.

9. Tsunokawa Y, Takebe N, Nozawa S, Kasamatsu T, Gissmann L, zur Hausen H, Terada M and Sugimura T: Presence of human papillomavirus type-16 and type-18 DNA sequences and their expression in cervical cancers and cell lines from Japanese patients. Int J Cancer 37: 499-503, 1986.

10. Takei Y, Kadomatsu K, Yuasa K, Sato W and Muramatsu T: Morpholino antisense oligomer targeting human midkine: its application for cancer therapy. Int J Cancer 114: 490-497, 2005.

11. Minakuchi Y, Takeshita F, Kosaka N, Sasaki H, Yamamoto Y, Kouno M, Honma K, Nagahara S, Hanai K, Sano A, Kato T, Terada $\mathrm{M}$ and Ochiya T: Atelocollagen-mediated synthetic small interfering RNA delivery for effective gene silencing in vitro and in vivo. Nucleic Acids Res 32: e109, 2004.

12. Hanai K, Kurokawa T, Minakuchi Y, Maeda M, Nagahara S, Miyata T, Ochiya T and Sano A: Potential of atelocollagenmediated systemic antisense therapeutics for inflammatory disease. Hum Gene Ther 15: 263-272, 2004.

13. Ochiya T, Nagahara S, Sano A, Itoh $\mathrm{H}$ and Terada M: Biomaterials for gene delivery: atelocollagen-mediated controlled release of molecular medicines. Curr Gene Ther 1: 31-52, 2001.

14. Ochiya T, Takahama Y, Nagahara S, Sumita Y, Hisada A, Itoh H, Nagai Y and Terada M: New delivery system for plasmid DNA in vivo using atelocollagen as a carrier material: the Minipellet. Nat Med 5: 707-710, 1999.

15. Takei Y, Kadomatsu K, Yuzawa Y, Matsuo S and Muramatsu T: A small interfering RNA targeting vascular endothelial growth factor as cancer therapeutics. Cancer Res 64: 3365-3370, 2004.

16. Takei Y, Kadomatsu K, Itoh H, Sato W, Nakazawa K, Kubota S, Muramatsu T: 5'-,3'-inverted thymidine-modified antisense oligodeoxynucleotide targeting midkine. Its design and application for cancer therapy. J Biol Chem 277: 23800-23806, 2002.

17. Takei Y, Kadomatsu K, Matsuo S, Itoh H, Nakazawa K, Kubota S and Muramatsu T: Antisense oligodeoxynucleotide targeted to Midkine, a heparin-binding growth factor, suppresses tumorigenicity of mouse rectal carcinoma cells. Cancer Res 61: 8486-8491, 2001.

18. Imai Y, Matsushima Y, Sugimura T and Terada M: Purification and characterization of human papillomavirus type 16 E7 protein with preferential binding capacity to the underphosphorylated form of retinoblastoma gene product. J Virol 65: 4966-4972, 1991

19. Monney L, Sabatos CA, Gaglia JL, Ryu A, Waldner H, Chernova T, Manning S, Greenfield EA, Coyle AJ, Sobel RA, Freeman GJ and Kuchroo VK: Th1-specific cell surface protein Tim-3 regulates macrophage activation and severity of an autoimmune disease. Nature 415: 536-541, 2002.

20. Hall AH and Alexander KA: RNA interference of human papillomavirus type 18 E6 and E7 induces senescence in HeLa cells. J Virol 77: 6066-6069, 2003. 
21. Kohn DB, Sadelain M, Dunbar C, Bodine D, Kiem HP, Candotti F, Tisdale J, Riviere I, Blau CA, Richard RE, Sorrentino B, Nolta J, Malech H, Brenner M, Cornetta K, Cavagnaro J, High K and Glorioso J: American Society of Gene Therapy (ASGT) ad hoc subcommittee on retroviral-mediated gene transfer to hematopoietic stem cells. Mol Ther 8: 180-187, 2003.

22. Yoshinouchi M, Yamada T, Kizami M, Fen J, Koseki T, Ikeda Y, Nishihara T and Yamato K: In vitro and in vivo growth suppression of human papillomavirus 16-positive cervical cancer cells by E6 siRNA. Mol Ther 8: 762-768, 2003.

23. Butz K, Ristriani T, Hengstermann A, Denk C, Scheffner M and Hoppe-Seyler F: siRNA targeting of the viral E6 oncogene efficiently kills human papillomavirus-positive cancer cells. Oncogene 22: 5938-5945, 2003.

24. Jiang $\mathrm{M}$ and Milner J: Selective silencing of viral gene expression in HPV-positive human cervical carcinoma cells treated with siRNA, a primer of RNA interference. Oncogene 21: 6041-6048, 2002.

25. DeFilippis RA, Goodwin EC, Wu L and DiMaio D: Endogenous human papillomavirus E6 and E7 proteins differentially regulate proliferation, senescence, and apoptosis in HeLa cervical carcinoma cells. J Virol 77: 1551-1563, 2003.

26. Koivusalo R, Krausz E, Helenius H and Hietanen S: Chemotherapy-compounds in cervical cancer cells primed by reconstitution of p53 function after short interfering RNAmediated degradation of human papillomavirus 18 E6 mRNA: opposite effect of siRNA incombination with different drugs. Mol Pharmacol 68: 372-382, 2005.
27. Mantovani F and Banks L: Inhibition of E6 induced degradation of $\mathrm{p} 53$ is not sufficient for stabilization of p53 protein in cervical tumour derived cell lines. Oncogene 18: 3309-3315, 1999.

28. Dimri GP, Lee X, Basile G, et al: A biomarker that identifies senescent human cells in culture and in aging skin in vivo. Proc Natl Acad Sci USA 92: 9363-9367, 1995

29. Hu G, Liu W, Hanania EG, Fu S, Wang T and Deisseroth AB: Suppression of tumorigenesis by transcription units expressing the antisense E6 and E7 messenger RNA (mRNA) for the transforming proteins of the human papilloma virus and the sense mRNA for the retinoblastoma gene in cervical carcinoma cells. Cancer Gene Ther 2: 19-32, 1995.

30. Alvarez-Salas LM, Benitez-Hess ML and DiPaolo JA: Advances in the development of ribozymes and antisense oligodeoxynucleotides as antiviral agents for human papillomaviruses. Antivir Ther 8: 265-278, 2003.

31. Jiang M, Rubbi CP and Milner J: Gel-based application of siRNA to human epithelial cancer cells induces RNAi-dependent apoptosis. Oligonucleotides 14: 239-248, 2004. 